\title{
Effect of Change Effort in Raising Organizational Climate at the Kenya School of Government, Matuga Campus
}

\author{
John L. Napoo \\ Richard Nyambati \\ Kenya School of Government
}

\begin{abstract}
The study sought to examine Effect of Change Effort in Raising Organizational Climate at the Kenya School of Government, Matuga Campus. The study adopted descriptive survey design with a total of 6 faculty and 22 nonfaculty staff considered for the study. The research instrument was subjected to a panel of experts and a reliability coefficient of 0.72 was achieved. The data was analyzed using descriptive statistics. The study findings revealed that for change to take place, a climate supportive of change and trust between employees and management should prevail. The study concluded that change effort was successfully introduced at the Kenya School of Government, Matuga Campus. It is expected that the findings from the study will help all stakeholders understand the importance of raising organizational climate that will promote employee productivity.
\end{abstract}

Keywords: Change Effort, Employee Productivity, Organizational Climate, Raising

\section{Background of the Study}

Effective change effort is strategic in the achievement of organizational goals because of its influence on organizational climate, which in turn improves employee productivity. Subsequently, a stable organizational climate increases organizational capacity by attracting employee loyalty. However, ineffective change effort brings uncertainty, anxiety and disharmony among employees.

McMurray (2003), define organizational climate as the individuals' illustrative ideas and understanding of organizational components such as systems, structures, frameworks and practices. According to Litwin et al (2001) as cited by Zhang and Liu (2010), organizational climate is a group of measurable characteristics members perceive directly or indirectly in the work place. However, with a different view, Moghimi and Subramaniam (2013) described organizational climate as invisible values and beliefs that exist within employees' behavior and action. The study suggested that organizational climate constitute perceptions employees have of their work environment.

Nair (2006), reaffirmed that organizational climate currently is challenged by the increasing number of changes affecting organizations. Therefore, in order to survive and be relevant in a competitive market, organizations constantly seek to improve their performance through raising organizational climate. In concurrence with Nair (2006), Brown and Leigh (1996) as cited by Yee and Ananthalakshmi (2017) posited that organizational climate is becoming more important because of the need to guarantee the retention of individuals who directly benefit and add value to the performance of an organization.

In the same vein, Bisconti and Solomon (2003) as cited by Yee and Ananthalakshmi (2017) attest that, "an organizational climate that allows for a high level of autonomy and supports relationships among companions, supervisors and subordinates brings about more fulfilled workers". Further, Brown and Leigh (1996) as cited by Yee and Ananthalakshmi (2017) reaffirm that environments created by organizations, that employees treat as kind and in which they can utilize maximum capacity are viewed as a main source of competitive advantage as well as an important variable in effective organizations.

Research study by Kangis et al (2000), revealed that increased corporate effectiveness was realized with increased employees' participation in decision making, greater information sharing and support from the management. The study implied that change effort if managed well by the organization could result in change in behavior and perceptions of individuals which could lead to increased satisfaction, efficiency and productivity. This study therefore aimed at examining how change effort introduced in an organization can raise organizational climate in terms of structural, behavioral and technological variables. The results of the study will contribute to helping the management to design organizational strategies that could establish a stable organizational climate.

\section{Statement of the Problem}

The organizational operating environment of the $21^{\text {st }}$ Century has presented itself with complexity and dynamism of a multiplicity of factors resulting in new phenomenon in technological, political and socio-economic space. The need for change, stimulated by both domestic and international competition, is easily recognized. New materials, 
global competition and new technologies have made serious inroads into markets that an organization may have once dominated.

The objective of organizational change is often to increase the effectiveness and lower expenses. According to Cameron and Quinn (2011), ignoring the effects of organizational climate is one of the biggest barriers in implementing new change initiatives. They recommend to always starting with diagnosing and assessing the current status of the organizational climate before starting the change process. Both general factors (such as climate) and more specific factors (such as participation and support)may represent conditions necessary for a successful implementation of a change effort (Eby et al., 2000; Haffar et al., 2014).

As the need to create a stable organizational climate raises concern, it is not yet established why change effort introduced in an organization fail to yield desirable results. There is lack of sufficient evidence in the case of the Kenya School of Government, Matuga Campus with regard to the effect of change effort in raising organizational climate. This study therefore intended to determine effect of change effort in raising organizational climate at the Kenya School of Government, Matuga Campus.

\section{Literature Review}

\subsection{Organizational Change}

According to Nancy and Robert (2010), change is the process of assisting individuals and organizations in passing from an old way of doing things to a new way of doing things. To them, Change is a systematic approach in which the organization and individuals are prepared and supported to move from how things are done today to how they will be done in the future.

Jones (2004) described organizational change as "a process in which an organization optimizes performance as it works toward becoming its ideal state in order to increase its effectiveness and efficiency." In the same vein Sagimo (2002) viewed organizational change as "a planned attempt by management to improve the overall performance of individuals, groups and the organization by altering structures, behavior and technology." Both Jones (2004) and Sagimo (2002) concur that organization and management involvement in the effort to improve organizational performance results in improved workers morale, customer satisfaction, improved skills, high quality production and efficient service delivery.

From the foregoing, organizational change is therefore the process of moving the organization from the status quo to a desired state that leads to improved productivity and competitive advantage in the market place.

\subsection{Change Effort}

Change effort is a deliberate response to a significant threat or opportunity arising outside of the organization. This means that the organization needs to develop a sense of awareness of happenings in its operating environment in order to put in place changes that will keep it competitive in the market. From a management perspective, change effort is a product of understanding what causes change and what essentially need to be changed. As noted by Wilson (1994), causes of change can be classified into external and internal. External causes of change can be as a result of changes in the customer expectations, level of technology, activities of competitors,market place, national economy and government policy. Internal causes of change can be related to structure, culture,management philosophy and power control system.

Change effort in an organization is categorized into three:

\section{i. Structural Change}

According to Cliff (2012), a structural change may be as simple as implementing a no - smoking policy, or as involved in restructuring the company to meet the customer needs more effectively.

This implies that management in the course of normal business can successfully adjust the organization's strategy to achieve the intended goals or even the management can change the mission of the organization in response to the demands dictated by the external environment.

However, adjusting the strategy of the organization may involve changing its fundamental approach to doing business in regards to the markets it will target, the kinds of products it will sell, how they will be sold, its overall strategic orientation, the level of global activity, and its various partnerships and other joint-business arrangements.

\section{ii. Behavioral Change}

Robbins (2005) describes behavioral change as an effort to redirect and improve employee attitude (image), orshift culture, skills and knowledge bases. He advocates for the introduction of reinforcement by the management in order to produce changes in behavior. Organization can change its structure and policy by simply developing new 
rules and procedures, but this may not necessarily lead to behavioral change hence the need to create an organizational climate in which reinforcement comes in as an important organizational change variable.

\section{iii. Technological Change}

Change can range from minor shifts in procedure or technology to a revolutionary shift in roles within a society. Sagimo (2000), posited that "technological changes include any application of new ways to transform resources into products or services". These resources include new machines or equipment and techniques such as management information systems.

\subsection{Organizational Climate}

The origin of the conceptualization of organizational climate was conceivedby Kurt Lewin (1951) through his proposed field theory in which behavior (B) was considered as a function of person (P) and environment (E). Thereafter, organizational climate found its way into scholarly work where it has failed to secure a universal definition. Therefore, it is worth noting that as different definitions for organizational climate and metrics exist, its conceptualization was derived from single underlying assumption of environment and its value based description.

Organizational climate is defined as employees shared perceptions regarding procedures, policies and practices of an organization (Ostroff et al. 2003, Schneider and Reichers (1983), Schneider et al. 2011). This implies that organizational climate can be treated as the social setting of an organization as it is concerned with micro events experienced by the employees. As noted by McMurray et al (2010) organizational climate is a set of work environment properties that are perceived by employees as a main force that influences their behavior either directly or indirectly. Organizational climate therefore creates a psychological environment that is purely based on opinions made by individual members of an organization. Henceforth, every organization has a unique organizational climate that makes it different from other organizations.

Climate is a perception attributed to an organization and its subsystems, as demonstrated by the way an organization handles issues, its members and groups (Udai, 2006, Lavanya, 2011). The climate can either be positive or negative depending on the quality of the prevailing working environment. Therefore, in the context of an organization, positive climate exists when employees' contributions towards the performance of an organization are valued and respected while negative climate inhibits individuals' discretionary efforts (Harish and Mishra, 2006).

Four approaches have been put forward to explain the formation of organizational climate. These are:

\section{i. The Structural Approach}

Organizational climate in this approach is viewed as an attribute or characteristic of an organization. As noted by Moran and Volkwein (1992) structural approach distinctively explains the link between objective and perceptual measures of organizational climate. To them, the attributes ownership is the responsibility of an organization and it is independent of individual members' perceptions.

In support of this approach, it is conceived that the structure of an organization gives rise to organizational climate, which then forms the basis of perceptions by individual members. Schneider and Reichers (1983) described this approach as structural argument, or perceptual measurement - organizational attribute approach as coined by James and Jones (1974).

\section{ii. The Perceptual Approach}

According to Moran and Volkwein (1992), organizational climate originates from the individual. In this approach the individual formulates, interprets as well as develops situational responses that are psychologically acceptable. James and Jones (1974) described this approach as perceptual measurement - individual attribute approach.

\section{iii. The Interactive Approach}

This approach originates from structural and perceptual approaches. According to Ashforth (1985), interactive approach combines the structural approach objectivism and perceptual approach subjectivism. Moran and Volkwein (1992), attest that organizational climate result from the interaction of individuals in response to their situation which results in the shared agreement of organizational members. In this approach communication is key in establishing organizational climate.

\section{iv. The Cultural Approach}

This approach incorporates role of organizational culture as a key factor in organizational climate development. Moran and Volkwein (1992), contend that organizational climate is shaped by individuals in a group who freely interact and share a common frame of reference, organizational culture, as they learn to deal with the demands of 
the organization. Under this approach interaction of individuals is a major factor in the development of organizational climate.

\section{Justification for the Study}

The study is anchored on Lewin's Change Model. According to Kurt Lewin (1951), there exist three steps for change to be effective: unfreezing the present, moving from the present (transition) and freezing. Change becomes short lived when the model is not followed. However, for the change to be permanent the present must be dismantled, move from the present to the future and people and processes have to be put in place to ensure permanency.

Lewin (1951) conceived change in terms of current state and desired state (Chand, 2008, Beckhard and Harris, 1987).To Lewin (1951), there are driving forces that initiate change and restraining forces that resist change. Thus, the model is involved in identifying driving and restraining forces that are likely to influence group complacency and willingness to change.

In light of these propositions advanced by Lewin's model (1951) change effort can be planned and even the model can be applied when unplanned change occur; particularly when the probability of the occurrence of change is known. The Kenya School of Government, Matuga Campus has experienced similar change process depending on the prevailing driving and restraining forces of change as it strives to attain a stable organizational climate.

\section{Conceptual Framework}

The conceptual framework has been developed from retrieved literature and related theory.

\section{Independent Variable Intervening Variables Dependent Variable}

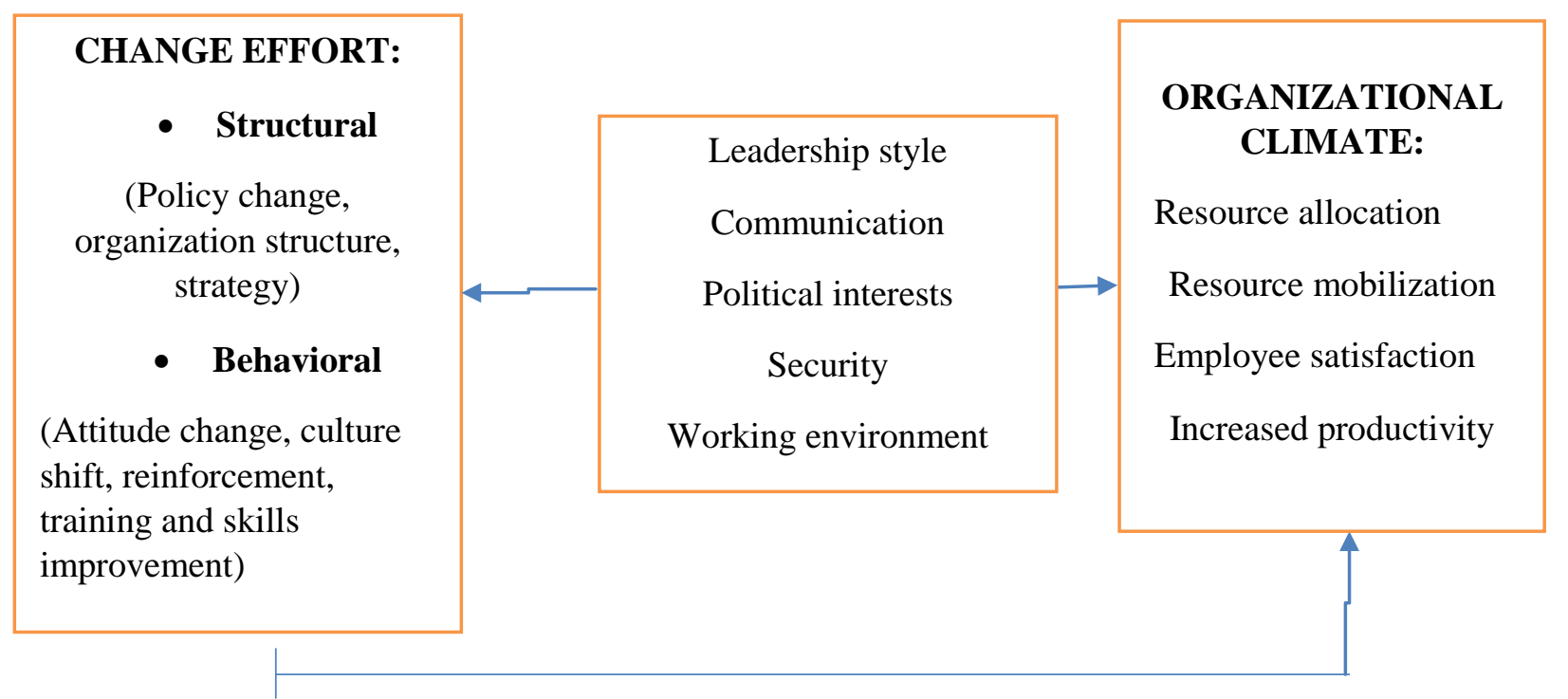

Figure 1: Change Effort in Raising Organizational Climate at the Kenya School of Government, Matuga Campus

\section{Research Question}

The study attempts to answer this research question: What effect does change effort have in raising organizational climate at the Kenya School of Government, Matuga Campus?

\section{Research Design and Methodology}

The study was conducted at the Kenya School of Government, Matuga Campus. This was done to ascertain whether the effect of change effort raised organizational climate with the expectation of increasing employee productivity. The study adopted descriptive survey. Simple random sampling method was used to determine the sample size.

\section{Table 1: Sample size}

\begin{tabular}{|l|l|l|}
\hline Designation & Population & Sample \\
\hline Faculty staff & 14 & 6 \\
\hline Non - faculty staff & 44 & 22 \\
\hline Total & $\mathbf{5 8}$ & $\mathbf{2 8}$ \\
\hline
\end{tabular}




\section{Results and Discussion}

Table 2: Change Effort in Raising Organizational Climate at the Kenya School of Government, Matuga Campus

\begin{tabular}{|c|c|c|c|c|c|}
\hline Type of Change & \multirow[b]{2}{*}{ Change Effort } & \multicolumn{4}{|c|}{ Frequency and Percentage Response } \\
\hline \multirow{4}{*}{$\begin{array}{l}\text { Structural } \\
\text { Change }\end{array}$} & & $\begin{array}{l}\text { Strongly } \\
\text { Agree }\end{array}$ & Agree & Disagree & $\begin{array}{l}\text { Strongly } \\
\text { Disagree }\end{array}$ \\
\hline & $\begin{array}{l}\text { There has been a change in the structure of } \\
\text { departments }\end{array}$ & $27(96.4 \%)$ & $1(3.6 \%)$ & $0(0.0 \%)$ & $0(0.0 \%)$ \\
\hline & $\begin{array}{l}\text { Organization service delivery process has } \\
\text { been improved }\end{array}$ & $21(75 \%)$ & $0(0.0 \%)$ & $7(25 \%)$ & $0(0.0 \%)$ \\
\hline & $\begin{array}{l}\text { Staff duties and responsibilities have been } \\
\text { modified by the changes in the organization } \\
\text { structure }\end{array}$ & $20(71.4 \%)$ & $2(7.2 \%)$ & $6(21.4 \%)$ & $0(0.0 \%)$ \\
\hline \multirow{4}{*}{$\begin{array}{l}\text { Behavioral } \\
\text { Change }\end{array}$} & $\begin{array}{l}\text { Changes in the departments are } \\
\text { communicated as they occur }\end{array}$ & $18(64.3 \%)$ & $9(32.1 \%)$ & $1(3.6 \%)$ & $0(0.0 \%)$ \\
\hline & $\begin{array}{l}\text { Staff have been trained or sensitized on the } \\
\text { skills needed to effect change }\end{array}$ & $24(85.7 \%)$ & $0(0.0 \%)$ & $4(14.3 \%)$ & $0(0.0 \%)$ \\
\hline & $\begin{array}{l}\text { Staff attitude towards instituted change is } \\
\text { positive }\end{array}$ & $18(64.3 \%)$ & $3(10.7 \%)$ & $7(25 \%)$ & $0(0.0 \%)$ \\
\hline & $\begin{array}{l}\text { Immediate supervisor is approachable, gives } \\
\text { direction and leads by example }\end{array}$ & $22(78.6 \%)$ & $3(10.7 \%)$ & $3(10.7 \%)$ & $0(0.0 \%)$ \\
\hline \multirow{3}{*}{$\begin{array}{l}\text { Technological } \\
\text { Change }\end{array}$} & $\begin{array}{l}\text { New systems and work methods have been } \\
\text { introduced in the departments }\end{array}$ & $18(64.3 \%)$ & $5(17.9 \%)$ & $4(14.3 \%)$ & $1(3.6 \%)$ \\
\hline & $\begin{array}{llll}\text { Staff have been assigned a desktop } \\
\text { computer or laptop }\end{array}$ & $21(75 \%)$ & $1(3.6 \%)$ & $5(17.9 \%)$ & $1(3.6 \%)$ \\
\hline & Offices have internet connectivity & $27(96.4 \%)$ & $0(0.0 \%)$ & $0(0.0 \%)$ & $1(3.6 \%)$ \\
\hline
\end{tabular}

8.1 There has been a change in the structure of departments

All respondents; $28(100.0 \%)$ agreed that there was a change in the structure of their respective departments.

8.2 Organization service delivery process has been improved

When asked whether organization service delivery process has been improved, 21 (75.0\%) of the respondents agreed while 7 (25.0\%) of the respondents disagreed.

\subsection{Staff duties and responsibilities have been modified by the changes in the organization structure}

Concerning whether duties and responsibilities have been modified by the changes in the organization structure, 22 (78.6\%) of the respondents agreed while $6(21.4 \%)$ of the respondentsdisagreed.

\subsection{Changes in the departments are communicated as they occur}

Regarding whether changes in the departments are communicated, 27 (96.4\%) of the respondents agreed while 1 (3.6\%) respondent disagreed.

\subsection{Staff have been trained or sensitized on the skills needed to effect change}

Most of the respondents $24(85.7 \%)$ agreed that they have been trained or sensitized on the skills required to effect change while $4(14.3 \%)$ of the respondents disagreed.

\subsection{Staff attitude towards instituted change is positive}

On attitude towards instituted change; majority of the respondents $21(75.0 \%)$ had positive attitude on instituted change while $7(25 \%)$ of the respondents had negative attitude.

\subsection{Immediate supervisor is approachable, gives direction and leads by example}

In relation to immediate supervisor being approachable, giving direction and leading by example; most of the respondents $25(89.3 \%)$ agreed with the statement whereas $3(10.7 \%)$ disagreed.

\subsection{New systems and work methods have been introduced in the departments}

On the introduction of new systems and work methods in the departments; majority of the respondents 23 (82.1\%) agreed while 5 (17.9\%) disagreed. 


\subsection{Staff have been assigned a desktop computer or laptop}

Most respondents $22(78.6 \%)$ agreed that they were either assigned a desktop computer or laptop while 6 (21.4\%) respondents disagreed.

\subsection{Offices have internet connectivity}

Majority of the respondents $27(96.4 \%)$ agreed that internet was available in their offices and $1(3.6 \%)$ respondent disagreed.

\section{Conclusion}

Based on the findings of the study, three main conclusions were made. First there existed awareness among staff of the change effort introduced at the Kenya School of Government, Matuga Campus. Secondly, raising a stable organizational climate requires the organization to establish a climate that is fully supportive of change.

Finally, for successful implementation of change effort in an organization, it was evident that a climate of mutual trust between employees and the management should prevail and be demonstrated through effective leadership, effective communication and motivation.

\section{References}

Ashforth, B. E. (1985). Climate formation: Issues and extensions.Academy of Management Journal, 10(4), 837847.

Beckhard, T. and Harris, M. (1987). Organizational transitions: Managing complex change.Wokingham. AddisonWesley.

Brown, S. P. and Leigh, T. W. (1996). A new Look at Psychological Climate and its Relationship to Job Involvement, Effort and Performance. Journal of Applied Psychology, 81(4), 358-368.

Cameron, K. S. and Quinn, R. E. (2011). Diagnosing and Changing Organizational Culture: Based on the Competing Values Framework (3rd ed.). San Francisco: Jossey-Bass.

Chand, T. (2008). Management of Organizations through Effective Change. New York, Free Press.

Cliff, M. (2012). Change Management and Information Technology. Birkbeck College: University of London.

Eby, L. T., Adams, D. M., Russell, J. E. A. and Gaby, S. H. (2000). Perceptions of Organizational Readiness for Change: Factors Related to Employees' Reactions to the Implementation of Team Based Selling. Human Relations, Vol. 53 No. 3, pp. 419-442.

Haffar, M., Al-Karaghouli, W. and Ghoneim, A. (2014). An Empirical Investigation of the Influence of Organizational Culture on Individual Readiness for Change in Syrian Manufacturing Organizations. Journal of Organizational Change Management, Vol. 27 No. 1, pp. 5-22.

Harish, S. and Mishra, D. P. (2006). A Study of the Organizational Climate of Professional Colleges.The ICFAI Journal of Organizational Behavior, Vol. 5, No. 2, pp. 48-61.

Isern, J. and Pung, A. (2007). Harnessing energy to drive organizational change. McKinsey Quarterly, 1, 16 - 19.

James, L. R. and Jones, A. P. (1974). Organizational Climate: A review of theory and research. Psychological Bulletin.

Jones, G. R. (2004). Organization Theory, Design and Change. New York: Addison-Wesley Publishing Company.

Kangis, P., Gordon D., and Williams, S. (2000). Organizational Climate and Corporate Performance: An Empirical Investigation.Management Decision, 38 (8): $531-540$.

Lavanya, M. (2011). Organizational Climate - 2. HRD TIMES, Vol. 13, No. 8, pp. 33-34.

Lewin, K. (1951). Field Theory in Social Science: Selected Theoretical Papers. New York: Harper \& Raw.

McMurray, A.J. (2003). The Relationship between Organizational Climate and Organizational Culture. Journal of American Academy of Business, 3 (1/2), 1-8.

McMurray, A.J., Pirola-Merlo, A., Saros, J.C., and Islam, M.M. (2010): Leadership, Climate, Psychological Capital, Commitment and Wellbeing in a Non-profit Organization. Leadership and Organization Development Journal, 31 (5), 436-457.

Moran, E. T. and Volkwein, J. F. (1992). The Cultural Approach to the Formation of Organizational Climate.Human Relations, vol. 45 (1), 19-47.

Nair, R. (2006).Climate studies and associated best practices to improve climate issues in the Workplace.Paper presented at Women in Engineering Programs and Advocates Network, Pennsylvania.

Nancy, L. and Robert, R. (2010). Managing Technological Change. Springer-Verlag, New York Inc.

Ostroff C, Kinicki A. J, and Tamkins M. M. 2003. Organizational culture and climate. In Handbook of Psychology: Industrial and Organizational Psychology, ed. W. C Borman, D. R Ilgen, R. J Klimoski, vol. 12, pp. 56593.New York: Wiley

Robbins, S. P. (2005). Organizational Behavior ( $11^{\text {th }}$ Ed.). Upper Saddle River, NJ: Pearson Education, Inc.

Sagimo, O. P. (2000). Management Dynamics: Towards Efficiency, Effectiveness, Competence and Productivity. East African Educational Publishers. 
Schneider B, Ehrhart M. G, and Macey W. H. 2011. Perspectives on organizational climate and culture. In APA Handbook of Industrial and Organizational Psychology: Vol. 1. Building and Developing the Organization, ed. S Zedeck, pp. 373-414. Washington, DC: Am. Psychol. Assoc.

Udai, P. (2006). Organizational Culture and Climate, First Edition: The ICFAI University Press, Hyderabad Wilson, T. (1994). A manual for change. Aldershot.

Yee, P. L. and Ananthalakshmi, M. (2017). A Study on the Impact of Organizational Climate on Employee Performance in a Malaysian Consultancy. International Journal of Accounting and Business Management, vol. 5 (No.1).

Zhang, J. and Liu, Y. (2010). Organizational Climate and its Effects on Organizational Variables: An Empirical Study. International Journal of Psychological Studies, vol. 2. 